\section{Erratum to: The Double Twist}

The online version of the original article can be found under doi:10.1007/s00283-009-9065-7.

\section{Erratum to: Math Intelligencer 2009 31(3): 57-61 DOI 10.1007/s00283-009-9065-7}

n The Mathematical Intelligencer, vol. 31, no. 3 (2009), Page 60, the Book Review: The Double Twist "From Ethnography to Morphodynamics" and "The Artist and the Mathematician: The Story of Nicolas Bourbaki, The Genius Mathematician Who Never Existed," reviewed by Osmo Pekonen, the reference to James M. Cargal's work, should read:

Cargal, James M. (2001). "The problem with algebraic models of marriage and kinship structure", The UMAP Journal 22 (4), pp. 345-353.

\author{
Osmo Pekonen \\ Agora Centre \\ University of Jyväskylä \\ P.O. Box 35, Jyväskylä \\ $\mathrm{Fl}-40014$, Finland \\ e-mail: osmo.pekonen@jyu.fi
}

